\title{
Caspase-3 inhibitor inhibits enterovirus D68 production
}

\author{
Wenbo Huo ${ }^{1,2 \dagger}$, Jinghua $\mathrm{Yu}^{1 \dagger}$, Chunyu Liu ${ }^{3}$, \\ Ting Wu ${ }^{4}$, Yue Wang ${ }^{5}$, Xiangling Meng ${ }^{2}$, \\ Fengmei Song ${ }^{2}$, Shuxia Zhang ${ }^{2}$, Ying $\mathrm{Su}^{2}$, \\ Yumeng Liu ${ }^{2}$, Jinming Liu' ${ }^{2}$, Xiaoyan $\mathrm{Yu}^{2}$, \\ and Shucheng Hua ${ }^{6 *}$ \\ ${ }^{1}$ Institute of Virology and AIDS Research, The First Hospital of Jilin \\ University, Jilin University, Changchun 130000, P. R. China \\ ${ }^{2}$ Department of Experimental Pharmacology and Toxicology, School of \\ Pharmaceutical Science, Jilin University, Changhun 130000, P. R. China \\ ${ }^{3}$ Acupuncture Department, The Affiliated Hospital of Changchun \\ University of Chinese Medicine, Changchun 130000, P. R. China \\ ${ }^{4}$ Neonatal Intensive Care Unit, The First Hospital of Jilin University, \\ Jilin University, Changchun 130000, P. R. China \\ ${ }^{5}$ Department of Chemistry of Traditional Chinese Medicine, Changchun \\ University of Chinese Medicine, Changchun 130000, P. R. China \\ ${ }^{6}$ Department of Internal Medicine, The First Hospital of Jilin University, \\ Jilin University, Changchun 130000, P. R. China
}

(Received May 8, 2020 / Revised Jun 19, 2020 / Accepted Jun 22, 2020)

Enterovirus D68 (EVD68) is an emerging pathogen that recently caused a large worldwide outbreak of severe respiratory disease in children. However, the relationship between EVD68 and host cells remains unclear. Caspases are involved in cell death, immune response, and even viral production. We found that caspase-3 was activated during EVD68 replication to induce apoptosis. Caspase-3 inhibitor (Z-DEVDFMK) inhibited viral production, protected host cells from the cytopathic effects of EVD68 infection, and prevented EVD68 from regulating the host cell cycle at G0/G1. Meanwhile, caspase- 3 activator (PAC-1) increased EVD68 production. EVD68 infection therefore activates caspase- 3 for virus production. This knowledge provides a potential direction for the prevention and treatment of disease related to EVD68.

Keywords: EVD68, caspase-3, apoptosis, viral production, host-pathogen interaction

\section{Introduction}

Human enterovirus 68 (EVD68) was originally isolated in California in 1962 from four children with respiratory illness. Since that time, reports of EVD68 infection have been scarce; however, over the past 10 years, EVD68 infection outbreaks have been reported in Italy, the United States, Germany, China, and several other countries (Esposito et al., 2015; Far-

\footnotetext{
${ }^{\dagger}$ These authors contributed equally to this work.

${ }^{*}$ For correspondence. E-mail: shuchenghua@126.com; Tel./Fax: +86-4318783235

Copyright (c) 2020, The Microbiological Society of Korea
}

rell et al., 2015; Reiche et al., 2015; Zhang et al., 2015; Carballo et al., 2019; Kamau et al., 2019; Messacar and Tyler, 2019), with a record number of confirmed cases in 2014 (http:// www.cdc.gov/non-polio-enterovirus/about/ev-d68.html). EVD68 is associated with respiratory illness, neurological complications, and even death among children. Unfortunately, there are still no available vaccines or medicines, which may be largely because the pathogenic mechanism of EVD68 has not been well explained.

EVD68 belongs to genus Enterovirus (family Picornaviridae). Human enterovirus (HEV) species are currently divided into HEV-A, -B, -C, and -D according to their molecular and biological characteristics (Oberste et al., 1999a, 1999b). EVD68 belongs to the HEV-D serotype but is biologically more similar to human rhinoviruses, which are related to respiratory diseases (Smura et al., 2010). Our previous studies revealed that infection with EVD68 or coxsackievirus A6 (assigned to the HEV-A serotype) induces G0/G1 cell cycle arrest (Wang et al., 2017, 2018), while human enterovirus 71 and coxsackievirus A16 (HEV-A serotype) manipulate the host cell cycle at $\mathrm{S}$ phase in order to promote their own viral replication $(\mathrm{Yu}$ et al., 2015). Different enteroviruses therefore show similarities and differences in regulating the host cell cycle. Knowing and targeting these similarities and differences will aid development of both broad-spectrum and highly effective specific anti-enterovirus drugs.

Enterovirus 71 (Song et al., 2018) and coxsackievirus A16 (Li et al., 2014) activate caspase-3 and induce apoptosis, while coxsackievirus A6 induces necroptosis independently of caspase-3 activation (Zhang et al., 2020). However, it is not clear whether EVD68 activates caspase-3 and induces apoptosis. Furthermore, our previous studies found that caspase- 3 inhibitor (Z-DEVD-FMK) inhibits enterovirus 71 production (Song et al., 2018) but does not affect coxsackievirus A6 production (Zhang et al., 2020). It is not clear whether caspase3 inhibitor inhibits EVD68 production.

Apoptosis is a well-studied mechanism of viral pathogenesis (Chang et al., 2004; Shi et al., 2012; Lu et al., 2013). Members of the caspase family of protease enzymes play important roles in apoptosis (Salvesen and Dixit, 1997; Villa et al., 1997; Hengartner, 2000). Numerous viruses avoid caspase activation that inhibits virus replication (Henderson et al., 1993; Rao et al., 1997; Hardwick, 1998); by contrast, some viruses activate caspases, especially caspase- 3 , to promote their own replication (Wurzer et al., 2003; Martin et al., 2007; Richard and Tulasne, 2012; Song et al., 2018). In this study, we confirmed that EVD68 replication induces apoptosis by activating caspase-3. A caspase- 3 inhibitor decreased EVD68 production to protect host cells from damage. Therefore, caspase3 inhibitors might represent a useful strategy for anti-EVD68 vaccine or drug development. 


\section{Materials and Methods}

\section{Virus and cells}

The US/KY/14-18953 (ATCC, VR-1825D) strain of EVD68 was propagated in human rhabdomyosarcoma RD cells (CCL$136)$, and the supernatants were collected and stored at $-80^{\circ} \mathrm{C}$. RD cells were purchased from the ATCC. Cells were maintained in Dulbecco's modified Eagle's medium (DMEM) (Hyclone) supplemented with 10\% fetal bovine serum (FBS) (GIBCO BRL).

\section{Viral titer determination}

Viral titers were determined by measuring the $50 \%$ tissue culture infective dose (TCID50) in a microtitration assay using RD cells, as described by Gay et al. (2006) and Reed (1983).

\section{Hoechst 33258 staining}

The nuclear stain Hoechst 33258 (Sigma) was used to visualize nuclear changes by fluorescence microscopy. Briefly, RD cells were plated in 6 -well plastic culture dishes $\left(4 \times 10^{5}\right.$ cells/well $)$, infected with EVD68 at an MOI of 2 for $24 \mathrm{~h}$ when obvious cell death could be found, fixed in $3.7 \%$ formaldehyde for $1 \mathrm{~h}$, washed with PBS, then stained with $5 \mathrm{mg} / \mathrm{L}$ Hoechst 33,258 for $30 \mathrm{~min}$. Nuclear changes were observed by fluorescence microscopy at excitation wavelength $350 \mathrm{~nm}$ with a $460 \mathrm{~nm}$ emission filter (Leica).

\section{Propidium iodide (PI) staining}

At the indicated time point, RD cells were stained with $4.5 \mu \mathrm{M}$ of PI (40747-B, Yeasen) in buffer (40747-C, Yeasen) for 15 min at room temperature. Morphological changes were observed and photographed under a light microscope (Olympus). PI staining was observed using fluorescence microscopy at excitation wavelength $488 \mathrm{~nm}$ with a $630 \mathrm{~nm}$ emission filter (Leica).

\section{Determination of DNA fragmentation by agarose gel elec- trophoresis}

Cells were trypsinized after EVD68 infection for 0, 12, 24, and $36 \mathrm{~h}$, and both adherent and floating cells were collected by centrifugation at $1,000 \times g$ for 5 min according to the protocol of Yu et al. (2007). The cell pellet was suspended in cell lysis buffer (10 mM Tris- $\mathrm{HCl}$; $\mathrm{pH} 7.4,10 \mathrm{mM}$ EDTA; $\mathrm{pH} 8.0,0.5 \%$ Triton-100) and kept at $4^{\circ} \mathrm{C}$ for $30 \mathrm{~min}$. The lysate was centrifuged at $25,000 \times g$ for $20 \mathrm{~min}$. The supernatant was incubated with $20 \mathrm{mg} / \mathrm{ml} \mathrm{RNase} \mathrm{A}(2 \mathrm{ml})$ at $37^{\circ} \mathrm{C}$ for $1 \mathrm{~h}$, then incubated with $20 \mathrm{mg} / \mathrm{ml}$ proteinase $\mathrm{K}(2 \mathrm{ml})$ at $37^{\circ} \mathrm{C}$ for $1 \mathrm{~h}$. The supernatant was mixed with $5 \mathrm{M} \mathrm{NaCl}$ $(20 \mathrm{ml})$ and isopropanol $(120 \mathrm{ml})$ at $-20^{\circ} \mathrm{C}$ overnight, and then centrifuged at $25,000 \times g$ for $15 \mathrm{~min}$. After drying, DNA was dissolved in TE buffer (10 mM Tris-HCl; pH 7.4, $1 \mathrm{mM}$ EDTA; pH 8.0) and separated using $2 \%$ agarose gel electrophoresis at $100 \mathrm{~V}$ for $50 \mathrm{~min}$.

\section{Caspase-3 inhibitor treatment or caspase-3 activator treat- ment}

Caspase-3 inhibitor treatment was according to the me- thod of Song et al. (2018). RD cells were pre-treated with $0.05 \%$ DMSO in $10 \%$ DMEM or $20 \mu \mathrm{M}$ caspase- 3 inhibitor (Z-DEVD-FMK, ApexBio, A1920) for $2 \mathrm{~h}$ and then washed with PBS and infected with EVD68 at an MOI of 2 or mocktreated for $2 \mathrm{~h}$. Cells were then washed again with PBS and re-treated with $0.05 \%$ DMSO in $10 \%$ DMEM or $20 \mu \mathrm{M}$ caspase-3 inhibitor for the indicated times.

For caspase- 3 activator treatment, RD cells were infected with EVD68 at an MOI of 2 or mock-treated for $2 \mathrm{~h}$. Cells were then washed again with PBS and treated with $0.05 \%$ DMSO in $10 \%$ DMEM, or $0.2 \mu \mathrm{M}$ or $0.5 \mu \mathrm{M}$ of caspase- 3 activator (PAC-1, A8177, Apexbio) for the indicated times.

\section{Quantitative reverse-transcription PCR}

Total RNA was extracted using Trizol reagent (GIBCO BRL) as specified by the manufacturer. The RNA was treated with DNAse (DNase I-RNase-Free, Ambion) to remove any contaminating DNA before $200 \mathrm{ng}$ of RNA was reverse-transcribed using oligo dT primers and a High Capacity cDNA RT Kit (Applied Biosystems) in a $20 \mu \mathrm{l}$ reaction as specified by the manufacturer. For quantitative PCR, template cDNA was added to a $20 \mu \mathrm{l}$ reaction with SYBR GAPDH. Forward and reverse primer sequences for VP1 were $5^{\prime}$-AGCACCC ACAGGCCAGAACACAC- $3^{\prime}$ and $5^{\prime}$-ATCCCGCCCTACT GAAGAAACTA-3', respectively, and those for GAPDH were $5^{\prime}$-GCAAATTCCATGGCACCGT- $3^{\prime}$ and $5^{\prime}$-TCGCCCCAC TTGATTTTGG-3', respectively. Amplification was carried out using an ABI Prism 7,000 for 40 cycles with the following conditions: initial denaturation at $95^{\circ} \mathrm{C}$ for $10 \mathrm{~min} ; 40$ cycles of $95^{\circ} \mathrm{C}$ for $15 \mathrm{sec}$ and $60^{\circ} \mathrm{C}$ for $1 \mathrm{~min}$; one cycle of $95^{\circ} \mathrm{C}$ for $1 \mathrm{~min}, 55^{\circ} \mathrm{C}$ for $30 \mathrm{sec}$, and $95^{\circ} \mathrm{C}$ for $30 \mathrm{sec}$. Fold changes were calculated relative to GAPDH using the $\Delta \Delta \mathrm{Ct}$ method for gene-coding sequence analysis as described by Wang et al. (2017).

\section{Caspase activity assay and cell number counting}

Caspase activity was analyzed using caspase-3/7 (Promega, G8090), caspase-8 (Promega, G8200), and caspase-9 (Promega, G8210) assays according to the manufacturer's instructions. RD cells were lysed using the manufacturer-provided homogeneous caspase- $3 / 7$ reagent at $24 \mathrm{~h}$ post-infection. The lysates were incubated at room temperature for $1.5 \mathrm{~h}$ before being read in a fluorometer at $485 / 530 \mathrm{~nm}$. Luminescence values were detected using a Fluoroskan Ascent FL (Thermo Scientific), and cell numbers in corresponding groups were counted using a standard medical blood counter. Caspase activity was calculated per cell.

\section{Cell cycle analysis by flow cytometry}

Nuclear DNA content was detected using PI staining and fluorescence-activated cell sorting (FACS). Briefly, adherent cells were collected and fixed in $1 \mathrm{ml}$ of cold $70 \%$ ethanol overnight at $4^{\circ} \mathrm{C}$, then resuspended in staining buffer $(50 \mu \mathrm{g} / \mathrm{ml}$ PI [Sigma] and $20 \mu \mathrm{g} / \mathrm{ml} \mathrm{RNase} \mathrm{in} \mathrm{PBS)} \mathrm{for} 2 \mathrm{~h}$ at $4^{\circ} \mathrm{C}$. Ten thousand PI-stained cells were analyzed using FACS (FACScan; BD). ModFit LT, version 2.0 (Verity Software House) was used for data analysis. 


\section{Immunoblot analysis}

Virus-infected and mock-infected cells were collected and washed once with PBS. Cells were lysed directly in sodium dodecyl sulfate (SDS) sample buffer (60 mM Tris- $\mathrm{HCl}$; $\mathrm{pH}$ 6.8, $2 \%$ SDS, $10 \%$ glycerol, $5 \%$ 2-mercaptoethanol, $0.01 \%$ bromophenol blue) followed by boiling for $10 \mathrm{~min}$. Whole-cell lysates were further subjected to SDS-PAGE. Proteins were transferred to nitrocellulose membranes (Bio-Rad) and detected with the corresponding primary antibody: anti-cleaved caspase-3 (Proteintech, 19677-1-AP), anti-VP1 polyclonal antibody (Genetex), anti-histone (GenScript), or anti-tubulin (Proteintech). Mouse and rabbit secondary antibodies were obtained from Proteintech.

\section{Statistical analyses}

Data are presented as the mean \pm standard deviation (SD). The Student's $t$-test was used to assess between-group differences, and the post hoc test of one-way ANOVA in SPSS 10.0 was used to assess multiple-group differences. $P$ values of $<$ 0.05 were considered statistically significant.

\section{Results}

\section{EVD68 infection induces apoptosis}

Considering that a number of viruses induce apoptosis during viral replication (Wurzer et al., 2003; Wang et al., 2015), we wondered whether EVD68 induced apoptosis in host cells. Numerous cells were detached from the bottom of the dish and became round and condensed at $24 \mathrm{~h}$ post-infection (Fig. 1A-2) compared with those subjected to mock infection (Fig. 1A-1), which was consistent with morphological characteristics of apoptosis. Apoptotic cells also exhibited condensed chromatin. The fluorescent dye Hoechst 33258 is a nuclear stain that is taken up readily by apoptotic cells. Highly condensed chromosomes stain bright blue whereas staining of uncondensed DNA is weak. We observed increased fluore-
(A)
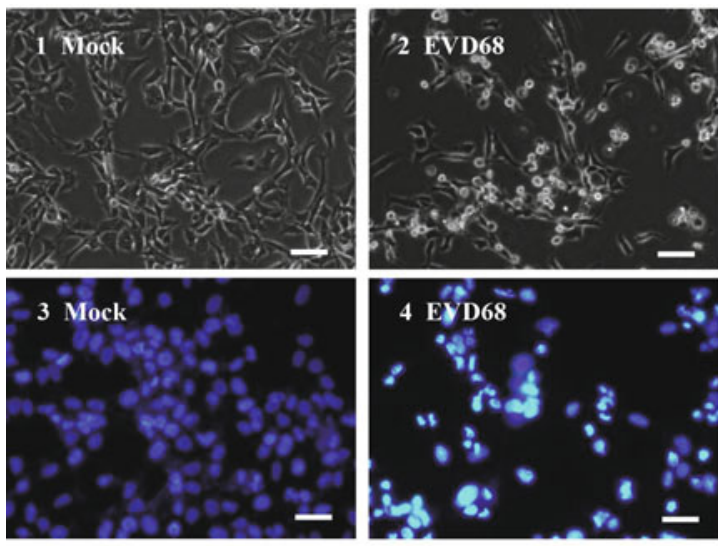

(C)

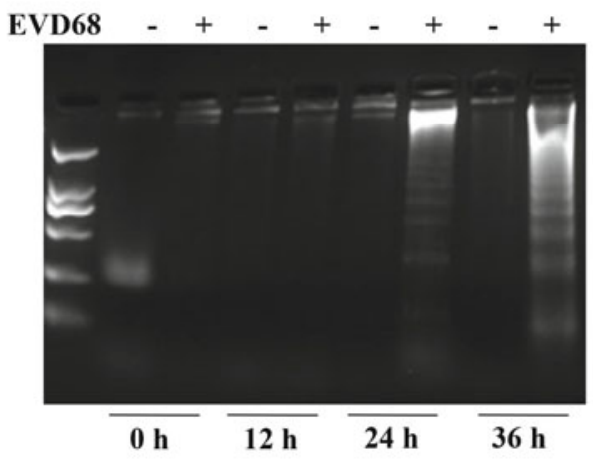

(B)
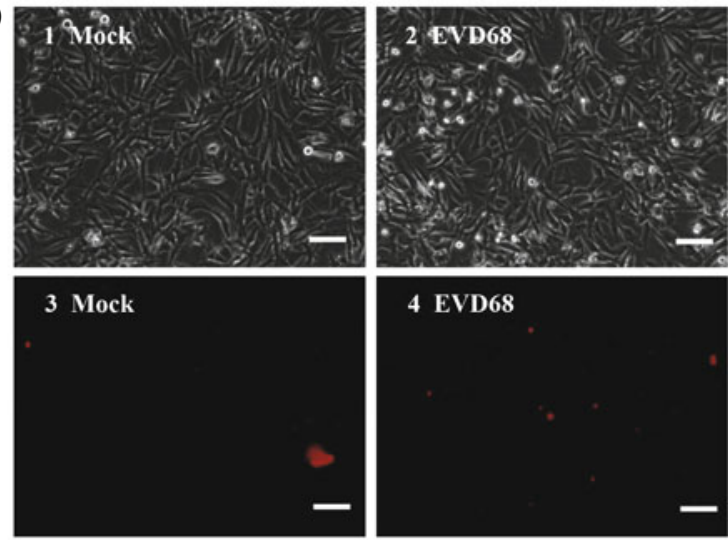

(D)

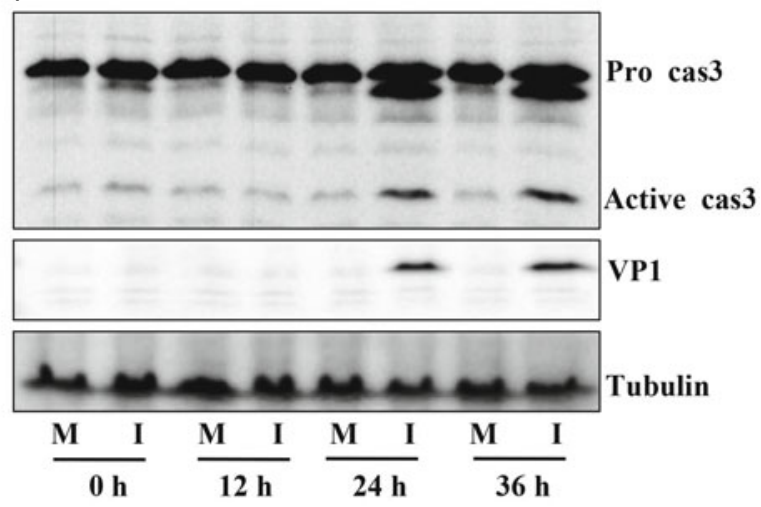

Fig. 1. EVD68 induces apoptosis in RD cells. (A) Cell death and nuclear condensation in EVD68-infected cells. Cells were stained with Hoechst 33258 after $24 \mathrm{~h}$ of infection. Round, floating cells and condensed nuclei were observed by light microscopy (upper panel) or fluorescence microscopy (lower panel). Data are representative of three individual experiments $(n=3)$. Bars $=20 \mu \mathrm{m}$. (B) Cell morphological analysis using propidium iodide staining after $24 \mathrm{~h}$ of infection with EVD68 $(\mathrm{MOI}=2)$. Round, floating cells and intact cell membranes were observed at $24 \mathrm{~h}$ post-infection using light microscopy (upper panel) or fluorescence microscopy (lower panel). Results are representative of three independent experiments $(\mathrm{n}=3)$. Bars $=20 \mu \mathrm{m}$. (C) DNA fragmentation at $0,12,24$, and $36 \mathrm{~h}$ post-infection with EVD68 at an MOI of 2. DNA fragmentation appeared at $24 \mathrm{~h}$ and $36 \mathrm{~h}$. (D) Cleaved caspase-3 abundance analyzed by immunoblotting at $0,12,24$, and $36 \mathrm{~h}$ post-infection with EVD68 at an MOI of 2 . Caspase 3 was activated at $24 \mathrm{~h}$ and $36 \mathrm{~h}$. Tubulin is shown as a loading control. Results are representative of three independent experiments. EVD68, EVD68-infected; M, mock-infected; I, EVD68-infected; Pro cas3, Pro caspase-3; Active cas3, Active caspase-3. 
scence in nuclei of RD cells at $24 \mathrm{~h}$ after infection with EVD68 (Fig. 1A-4) compared to that following mock infection (Fig. 1A-3), which was consistent with the observed morphology after mock infection (Fig. 1A-1) and EVD68 infection (Fig. 1A-2).

To further distinguish the cell death induced by EVD68 infection, we utilized propidium iodide (PI) to assess plasma membrane rupture. Large PI molecules are unable to enter cells with intact plasma membranes but can enter cells with ruptured membranes; apoptotic cells have intact plasma membranes that exclude PI (Zhang et al., 2020). Infection by EVD68 induced obvious cytopathic effects (Fig. 1B-2) compared to mock infection (Fig. 1B-1); however, we did not observe cellular PI staining after EVD68 infection (Fig. 1B-4), similar to mock infection (Fig. 1B-3), suggestive of cells with intact plasma membranes following EVD68-induced cell death. DNA laddering is a distinctive feature of apoptosis that can be analyzed by gel electrophoresis (Yu et al., 2017). We observed clear DNA laddering in EVD68-infected cells at $24 \mathrm{~h}$ and $36 \mathrm{~h}$ post-infection, but not in mock-infected cells (Fig. 1C). Therefore, the cell death induced by EVD68 was apoptosis.

Caspase-3 is responsible for the activation of caspase-activated DNase, which degrades DNA into fragments (Yu et al., 2007). We therefore analyzed the activation of caspase-3 at $24 \mathrm{~h}$ and $36 \mathrm{~h}$ post-infection when the DNA ladder appeared.

(A)

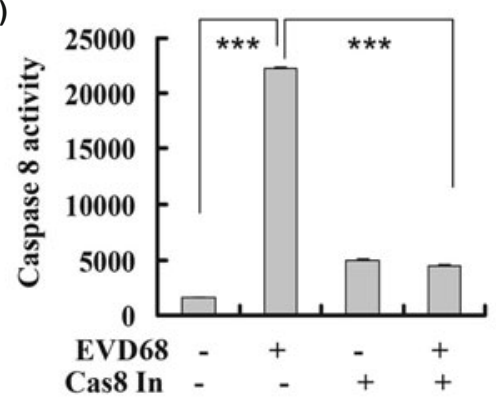

(C)

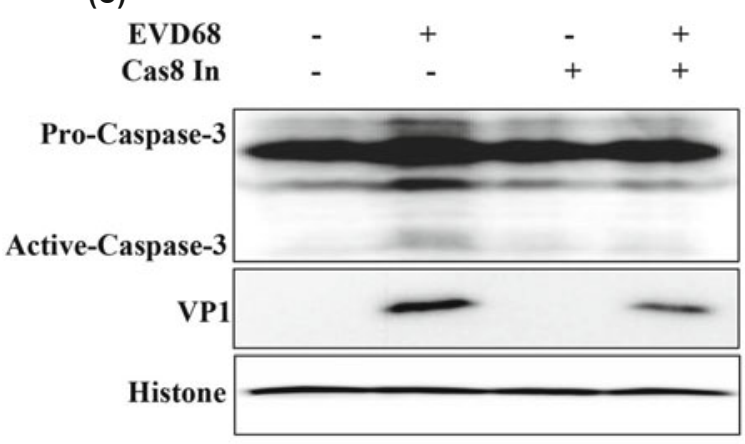

EVD68 infection activated caspase- 3 at $24 \mathrm{~h}$ and $36 \mathrm{~h}$ postinfection (Fig. 1D), further confirming that caspase- 3 is activated during EVD68-induced apoptosis.

Caspase- 8 and caspase- 9 proteins upstream of caspase- 3 are activated by EVD68 infection

Caspase- 8 and caspase- 9 are upstream proteins of caspase-3, and their activation can activate caspase-3 (Li et al., 2014). To investigate the mechanism of caspase- 3 activation by EVD68, we investigated whether caspase- 8 and caspase- 9 were activated by EVD68 infection of RD cells. EVD68 infection activated caspase- $8(P<0.001)$ (Fig. $2 \mathrm{~A})$ and caspase- $9(P<0.01)$ (Fig. 2B), which could be inhibited by caspase- 8 inhibitor $(P$ $<0.001)$ (Fig. 2A) or caspase-9 inhibitor $(P<0.001)$ (Fig. 2B), correspondingly.

Activation of caspase- 3 was inhibited when the activation of caspase- 8 or caspase- 9 was inhibited by the corresponding inhibitor (Fig. 2C and D). Furthermore, abundance of VP1 was also decreased (Fig. 2C and D). Therefore, EVD68 infection activates caspase- 8 and caspase- 9 before activating caspase-3.

\section{Caspase-3 inhibitor decreases EVD68 production}

Caspase- 3 inhibitor inhibits enterovirus 71 production, coxsackievirus B3, and influenza virus (Wurzer et al., 2003; Mar-

(B)

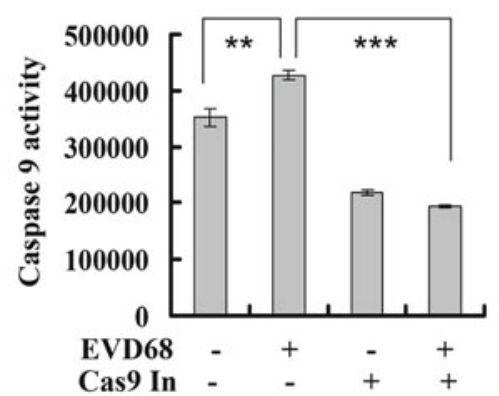

(D)

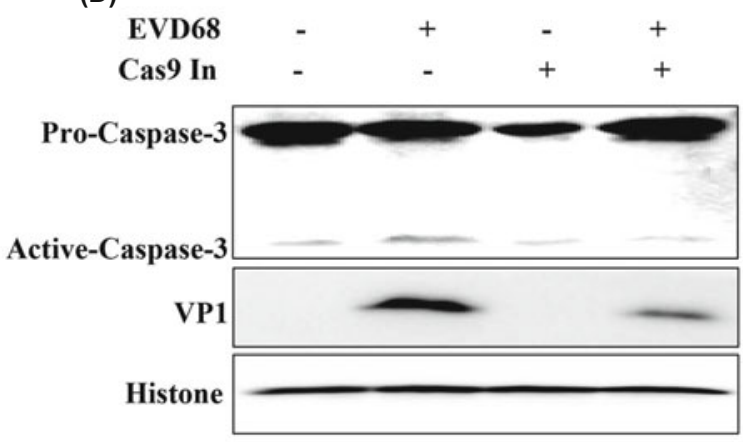

Fig. 2. Caspase-8 and caspase-9 activate caspase-3. (A) Caspase-8 activity following EVD68 infection. Luminescence values were detected at $24 \mathrm{~h}$ post-infection with EVD68 at an MOI of 2, with or without caspase-8 inhibitor. Capase-8 inhibitor reversed the EVD68-induced activation of caspase-8. Results are the mean \pm SD of three independent experiments. (B) Caspase-9 activity following EVD68 infection. Luminescence values were detected at $24 \mathrm{~h}$ post-infection with EVD68 at an MOI of 2, with or without caspase-9 inhibitor. Capase-9 inhibitor reversed the EVD68-induced activation of caspase-9. Results are the mean \pm SD of three independent experiments. (C) Abundance of caspase-3 and VP1 after caspase-8 inhibitor treatment. Histone is shown as a loading control. Results are representative of three independent experiments. (D) Abundance of caspase-3 and VP1 after caspase-9 inhibitor treatment. Histone is shown as a loading control. Results are representative of three independent experiments. Cas 8 In, caspase- 8 inhibitor; Cas 9 In, caspase-9 inhibitor. ${ }^{* *} P<0.01 ;{ }^{* *} P<0.001$. 
tin et al., 2007; Richard and Tulasne, 2012; Song et al., 2018), but does not inhibit coxsackievirus A6 production (Zhang et al., 2020). We therefore investigated whether caspase-3 inhibitor could inhibit EVD68 production. We used Z-DEVDFMK as a caspase-3 inhibitor, similar to our previous studies (Song et al., 2018; Zhang et al., 2020). RD cells were pretreated with $20 \mu \mathrm{M}$ Z-DEVD-FMK or $0.05 \%$ DMSO in $10 \%$ DMEM for $2 \mathrm{~h}$ and then washed with PBS before infecting with EVD68 at an MOI of 2 or mock infecting. After $2 \mathrm{~h}$, the cells were washed again and re-treated with $20 \mu \mathrm{M} Z$-DEVDFMK or $0.05 \%$ DMSO in 10\% DMEM for detecting EVD68 RNA levels (Fig. 3A). We confirmed the inhibitory effect of caspase-3 inhibitor on viral production by analyzing viral entry, viral genome replication, viral protein expression, and
TCID50 after caspase-3 inhibitor treatment. We used quantitative reverse-transcription PCR to assess the level of EVD68 viral genomic RNA at $2 \mathrm{~h}$ and $12 \mathrm{~h}$ post-infection. There was no difference in viral genomic RNA level between caspase-3 inhibitor treatment and the control treatment at either time point, indicating that caspase-3 inhibitor did not inhibit viral entry or viral replication (Fig. 3B). We then investigated EVD68 viral genomic RNA levels at $24 \mathrm{~h}$ post-infection, during viral maturation. Viral genome levels were decreased by caspase- 3 inhibitor treatment compared to the control treatment, indicating that the caspase- 3 inhibitor might affect viral maturation $(P<0.001)$ (Fig. 3C). Immunoblotting using VP1 antibody showed that caspase-3 inhibitor could decrease intracellular VP1 protein abundance at $24 \mathrm{~h}$ post-infection
(A)

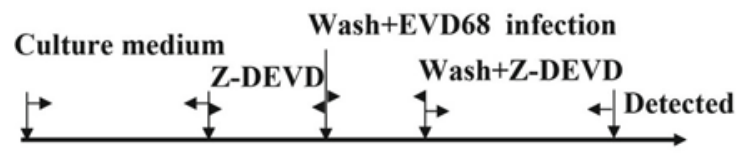

(B)

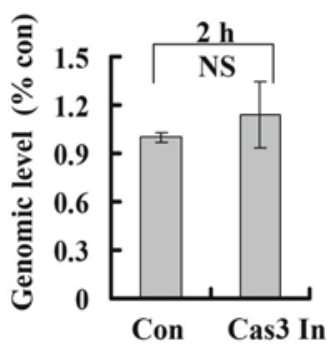

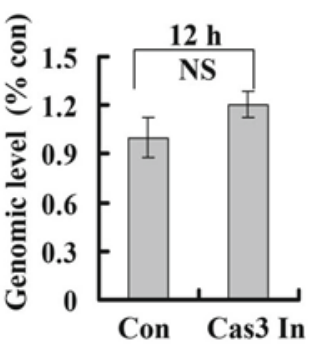

(E)

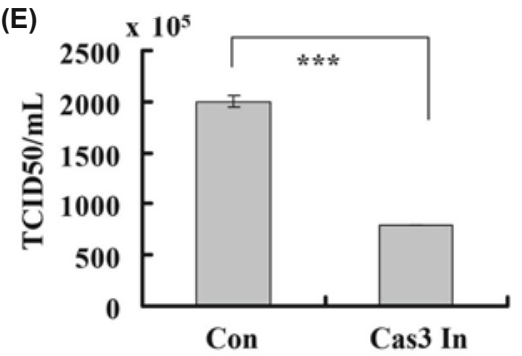

(F)

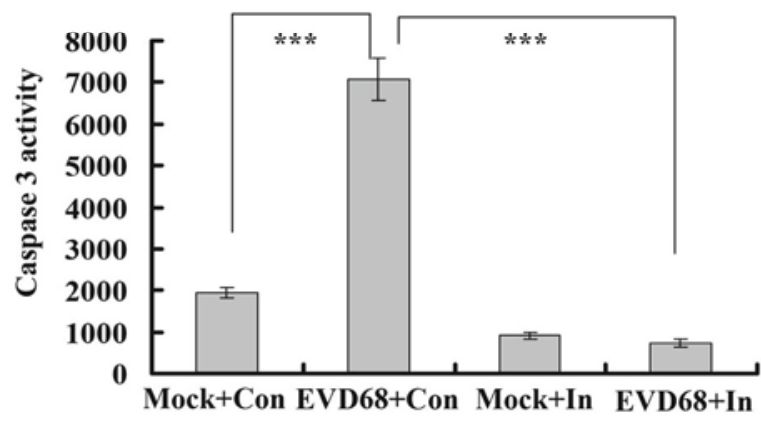

(D)

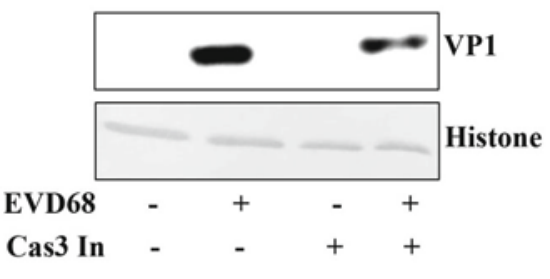

(G)

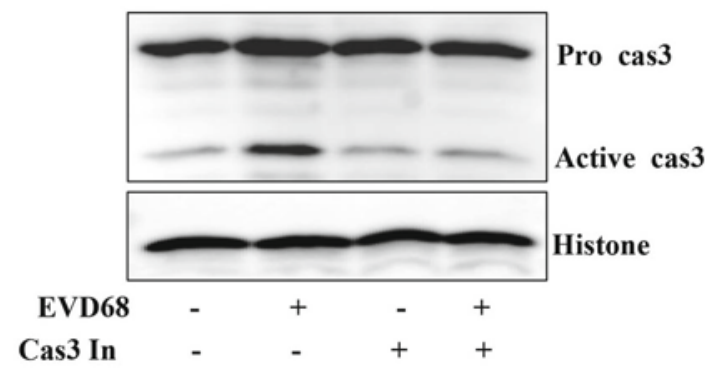

Fig. 3. Effect of caspase-3 inhibitor on EVD68 production. (A) Flow diagram of caspase-3 inhibitor (Z-DEVD-FMK) treatment. RD cells were pre-treated with $20 \mu \mathrm{M}$ Z-DEVD-FMK inhibitor (Z-DEVD) or 0.05\% DMSO in 10\% DMEM (Con) for $2 \mathrm{~h}$. Cells were then washed with PBS and mock-infected or infected with EVD68 $(\mathrm{MOI}=2)$. After $2 \mathrm{~h}$, cells were washed again with PBS and re-treated with $20 \mu \mathrm{M}$ Z-DEVD-FMK or 0.05\% DMSO in $10 \%$ DMEM for the indicated times. (B) Intracellular EVD68 RNA levels detected by quantitative reverse-transcription PCR in control or caspase-3 inhibitor-treated $\mathrm{RD}$ cells at $2 \mathrm{~h}$ and $12 \mathrm{~h}$ post-infection. Caspase- 3 inhibitor did not affect intracellular EVD68 genome levels at $2 \mathrm{~h}$ or $12 \mathrm{~h}$ post-infection. Results are the mean \pm SD of three independent experiments. (C) Intracellular EVD68 RNA levels detected by quantitative reverse-transcription PCR in control or caspase-3 inhibitor-treated RD cells at $24 \mathrm{~h}$ post-infection. Caspase-3 inhibitor decreased the level of EVD68 genomic RNA. Results are the mean \pm SD of three independent experiments. (D) VP1 abundance at $24 \mathrm{~h}$ post-infection determined by immunoblotting of cellular lysates after growth in control medium or caspase-3 inhibitor medium. Caspase-3 inhibitor decreased the level of viral protein. Results are representative of three independent experiments. (E) Quantitative analysis of TCID $50 / \mathrm{ml}$ at $24 \mathrm{~h}$ post-infection. Intracellular and supernatant progeny virions were titrated using RD cells. Caspase-3 inhibitor decreased the production of EVD68. Results are the mean \pm SD of three independent experiments. (F) Caspase3/7 activity assay of caspase-3 activity. Luminescence values were detected at $24 \mathrm{~h}$ post-infection with EVD68 at an MOI of 2. Caspase-3 inhibitor inhibited the activation of caspase-3. Results are the mean \pm SD of three independent experiments. (G) Abundance of active caspase-3 analyzed by immunoblotting at 24 h post-infection with EVD68 at an MOI of 2, with or without caspase-3 inhibitor. Histone is shown as a loading control. Results are representative of three independent experiments. Mock, mock-infected; Con, $0.05 \%$ DMSO in 10\% DMEM; EV, EVD68 infection; In, caspase-3 inhibitor; Cas3, caspase-3. NS, not significant. ${ }^{* *} P<0.001$. 
(Fig. 3D). Finally, we analyzed EVD68 production at $24 \mathrm{~h}$ post-infection by determining the TCID $50 / \mathrm{ml}$ of both intracellular and supernatant virions. The TCID50/ml of EVD68infected cells $\left(2,003.33 \pm 52.3 \times 10^{5}\right)$ was dramatically decreased by addition of caspase- 3 inhibitor $\left(789.07 \pm 1.91 \times 10^{5}\right)(P$ $<0.001$ ) (Fig. 3E). Therefore, caspase-3 inhibitor inhibits EVD68 production.

We next determined whether caspase-3 inhibitor (Z-DEVDFMK) efficiently inhibited the activity of caspase-3. Caspase activity assays confirmed that EVD68 infection increased caspase- 3 activity (EV + Con; 7,078.67 \pm 512.82 luminescence) compared to that in the mock-infected group (Mock + Con; $1,932.67 \pm 126.011$ luminescence $)(P<0.001)$, but that caspase- 3 inhibitor treatment reversed this activation $(\mathrm{EV}+\mathrm{In}$; $737.03 \pm 100.74$ luminescence $)(P<0.001$ versus $\mathrm{EV}+\mathrm{Con})$ (Fig. 3F). Immunoblotting further proved that EVD68 infection increased the abundance of activated caspase- 3 compared to mock infection, while caspase- 3 inhibitor reversed the effect of EVD68 infection (Fig. 3G). Therefore, caspase-3 inhibitor inhibits caspase-3 activation in EVD68-infected RD cells.

\section{Caspase-3 inhibitor inhibits apoptosis induced by EVD68 infection}

Viral infection usually leads to cell death, which might be necessary for viral replication but leads to damage of host cells (Holmes, 1975). To determine the effect of caspase-3 activation on apoptosis induced by EVD68, we observed morphological changes in RD cells infected with EVD68 after caspase-3 inhibitor treatment. Without inhibitor, numerous cells became more rounded and detached from the bottom of the culture dish at $24 \mathrm{~h}$ post-infection, indicating that EVD68 induced cell death (Fig. 4A). However, caspase-3 inhibitor kept cells alive after EVD68 infection (Fig. 4A). Cell number analysis confirmed that EVD68 infection $\left(56.33 \pm 11.84 \times 10^{4}\right)$ decreased cell number compared to mock infection (125 \pm $\left.12.49 \times 10^{4}\right)(P<0.01)$, whereas caspase-3 inhibitor $(98 \pm$ $\left.8.50 \times 10^{4}\right)$ increased the cell number of EVD68-infected cells compared to the control treatment group without inhibitor $\left(56.33 \pm 11.84 \times 10^{4}\right)(P<0.01)$ (Fig. 4B). Therefore, caspase-3 inhibitor inhibits cell death and protects host cells from damage induced by EVD68.
(A)
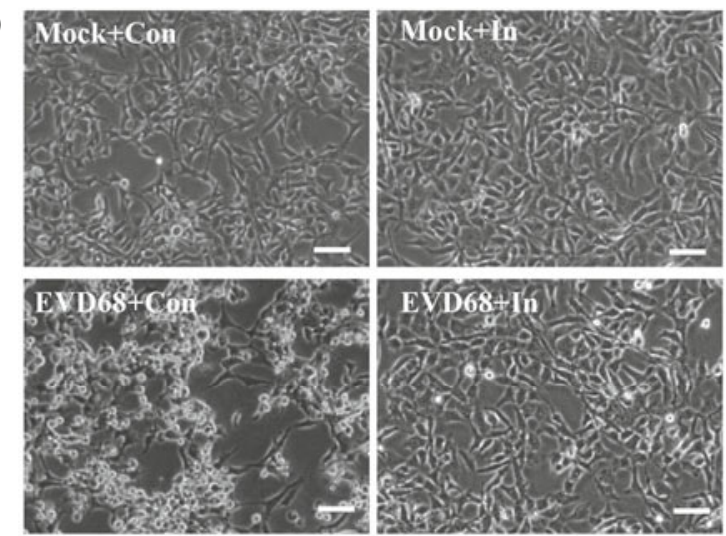

(C)

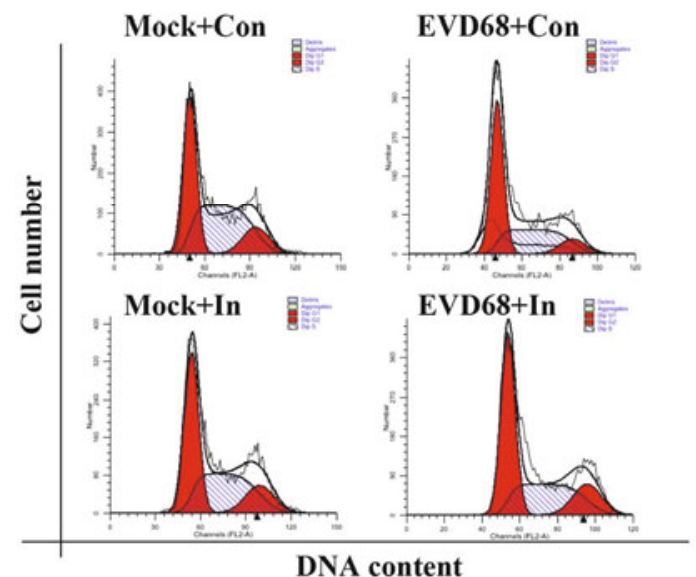

(B) x $10^{4} \quad 24 \mathrm{~h}$

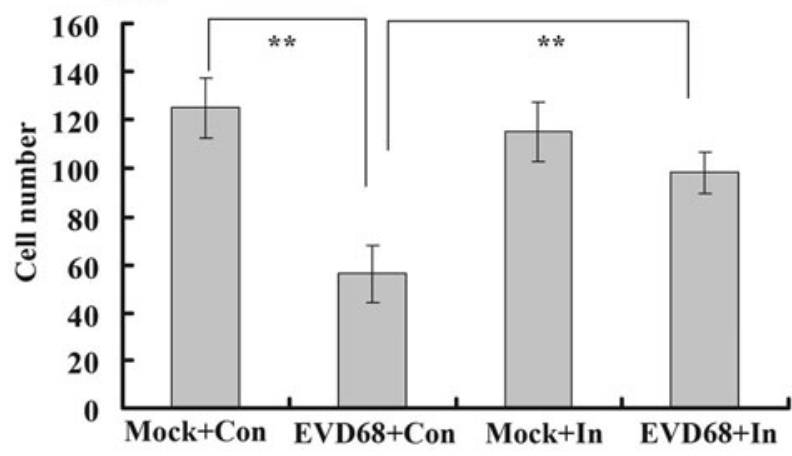

(D)

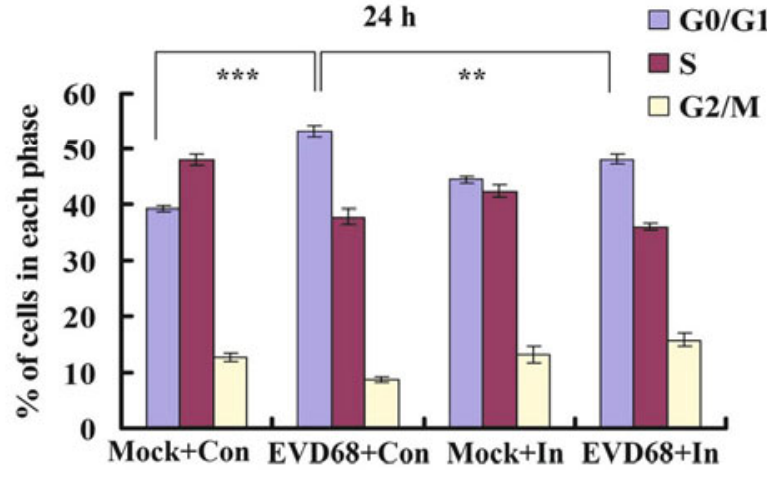

Fig. 4. Caspase-3 inhibitor blocks EVD68-induced cytopathic effects. (A) Morphological analysis of cell death after EVD68 infection in the presence and absence of caspase-3 inhibitor, assessed by light microscopy. Caspase-3 inhibitor decreased the cell death induced by EVD68. Results are representative of three independent experiments. Bars $=20 \mu \mathrm{m}$. (B) Cell number analysis after EVD68 infection in the presence and absence of caspase-3 inhibitor. Cell number was counted after trypan blue staining, and results are the mean \pm SD of three independent experiments. (C) Cell-cycle profiles determined by flow cytometry. (D) Percentage of cells in each phase of the cell cycle as analyzed by the ModFit LT program. Results are means \pm SD of three independent experiments. Mock, mock-infected; Con, 0.05\% DMSO in 10\% DMEM; EV, EVD68 infection; In, caspase-3 inhibitor. ${ }^{* *} P<0.01,{ }^{* *} P<0.001$. 
(A)

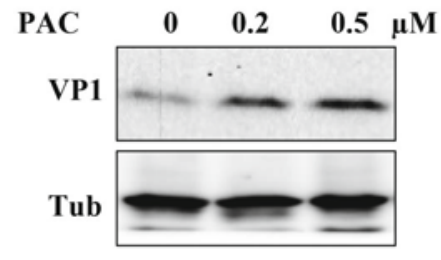

(B)

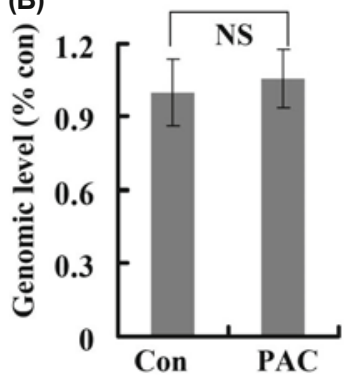

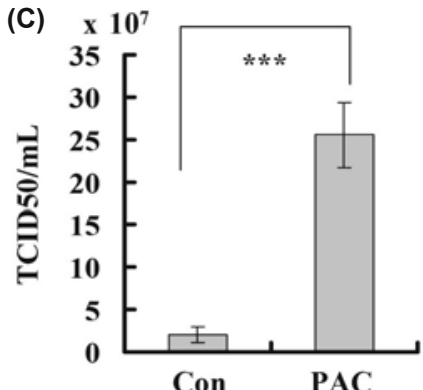

Fig. 5. Effect of caspase-3 activator on EVD68 production. (A) VP1 abundance at 24 h post-infection determined by immunoblotting of cellular lysates after growth in control medium or caspase- 3 activator medium $(0 \mu \mathrm{M}, 0.2 \mu \mathrm{M}$, or $0.5 \mu \mathrm{M})$. Caspase- 3 activator, PAC- 1 , increased the abundance of VP1. Tubulin is shown as a loading control. Results are representative of three independent experiments. (B) Intracellular EVD68 RNA levels detected by quantitative reverse-transcription PCR in control or caspase- 3 activator-treated RD cells at $12 \mathrm{~h}$ post-infection. Caspase-3 activator had no significant effect on the level of EVD68 genomic RNA in RD cells. Results are the mean \pm SD of three independent experiments. (C) Quantitative analysis of TCID50/ml at 24 h post-infection. Intracellular and supernatant virions were titrated using RD cells. Caspase-3 activator, PAC-1, increased the production of EVD68. Results are the mean \pm SD of three independent experiments. Con, $0.05 \%$ DMSO in 10\% DMEM; EV, EVD68 infection; PAC, PAC-1, caspase-3 activator. NS, not significant. ${ }^{* *} P<0.001$.

\section{Caspase-3 inhibitor prevents G0/G1 arrest induced by EVD68 infection}

Our previous study showed that EVD68 infection causes host cells to accumulate at G0/G1 phase to facilitate viral production (Wang et al., 2017). To determine the effect of caspase-3 inhibitor on the ability of EVD68 to manipulate the host cell cycle, we performed FACS to analyze cell cycle distribution. EVD68 infection $(53.23 \pm 1.06 \%)$ increased the percentage of G0/G1 phase cells compared to that in the mock infection group $(39.25 \pm 0.38 \%)(P<0.001)$; however, treatment with caspase- 3 inhibitor decreased the percentage of $\mathrm{G} 0 / \mathrm{G} 1$ phase cells to $48.02 \pm 0.88 \%(P<0.01)$ (Fig. $4 \mathrm{C}$ and $\mathrm{D})$. Therefore, caspase- 3 inhibitor reverses the G0/G1 phase arrest mediated by EVD68.

\section{Caspase-3 activator promotes EVD68 production}

Caspase- 3 is activated by virus infection (Chang et al., 2004; Shi et al., 2012; Lu et al., 2013). To further confirm the role of caspase-3 in EVD68 production, we used an activator of caspase-3, PAC-1 (Apexbio, A8177), which catalyzes the cleavage of pro-caspase- 3 into caspase- 3 . Increasing the dose of PAC-1 $(0 \mu \mathrm{M}, 0.2 \mu \mathrm{M}, 0.5 \mu \mathrm{M})$ increased the abundance of viral VP1 correspondingly (Fig. 5A), while $0.2 \mu \mathrm{M}$ PAC-1 did not affect viral genome replication at $12 \mathrm{~h}$ post-infection (Fig. 5B). However, $0.2 \mu \mathrm{M}$ PAC-1 increased the TCID50 of intracellular and supernatant virions at $24 \mathrm{~h}$ post-infection from $2.06 \pm 0.98 \times 10^{8}$ in the control treatment to $25.57 \pm$ $3.86 \times 10^{8}$ with PAC- $1(P<0.001)$ (Fig. 5 C). Therefore, the activator of caspase- 3 increased EVD68 production.

\section{Discussion}

EVD68 is an emerging pathogen that can cause severe respiratory disease and is associated with cases of paralysis, especially among children. Unfortunately, no vaccines or medicines are available to prevent or treat future outbreaks.

To confirm the pathogenic mechanism of EVD68 infection, we determined whether EVD68 induced apoptosis in an RD cell line. Cell morphology, nuclear morphology, plasma membrane integrity, DNA fragmentation, and caspase- 3 activation analysis confirmed that EVD68 infection leads to apoptosis, similar to EV71 (Chang et al., 2004), CA16 (Li et al., 2014), and other viruses (Wurzer et al., 2003; Richard and Tulasne, 2012; Song et al., 2018).

There are two main mechanisms of apoptosis. The extrinsic pathway, or the Fas death receptor pathway, activates caspase8 and caspase-10 in response to external stimuli. The intrinsic pathway, or mitochondrial pathway, activates cleavage of procaspase- 9 in response to internal stimuli. Initiator caspase- 8 and caspase- 9 activate caspase- 3 through proteolytic cleavage, resulting in cleavage of cellular target proteins and apoptosis (Li et al., 2014). In this study, EVD68 activated caspase- 8 and caspase-9, and then activated caspase-3, inhibiting caspase-8, or caspase-9 inhibited EVD68 production. Therefore, EVD68 activates both the extrinsic pathway and the intrinsic pathway for caspase- 3 activation.

Previous studies have demonstrated that caspase-3 inhibitor can inhibit EV71 production (Wurzer et al., 2003; Martin et al., 2007; Richard and Tulasne, 2012; Song et al., 2018) but not CA6 production (Zhang et al., 2020). In this study, we confirmed an inhibitory role of caspase- 3 inhibitor on EVD68 production.

To determine whether caspase-3 inhibitor attenuates EVD68 production, we performed a series of analyses of viral genome replication, viral protein expression, and the number of EVD68 virions. Our results demonstrate that caspase- 3 inhibitor does not affect viral entry or viral genome replication; however, caspase- 3 inhibitor blocks viral protein expression and decreases EVD68 production. Caspase-3 inhibitor blocks the induction of apoptosis by EVD68 to protect host cells and prevents EVD68 from regulating the host cell cycle for its own production. Therefore, caspase- 3 inhibitor inhibits production of EVD68 and EV71, but not CA6. Caspase-3 inhibitor is therefore not suitable for treatment of all enteroviruses, but has potential for treating EVD68 and EV71.

Caspase-3 inhibitor blocked EVD68 production, indicating that caspase- 3 might play an important role in viral production. To further confirm this hypothesis, we used an activator 
of caspase-3, PAC-1, after EVD68 infection. PAC-1 increased the abundance of viral protein in a dose-dependent manner, and promoted EVD68 production. Therefore, caspase- 3 activator promotes viral production. We conclude that caspase3 plays an important role in EVD68 production. Neither caspase- 3 inhibitor nor caspase-3 activator affected viral genome replication, indicating that caspase- 3 might not be involved in viral genome replication but might play a role in viral protein cleavage or in viral maturation. This will be investigated in a future study.

Our data support a model in which EVD68 activates caspase3 -associated apoptosis for its own production and further identify caspase-3 inhibition as a novel direction for the treatment and prevention of EVD68-related diseases.

\section{Acknowledgments}

This work was supported by the National Natural Science Foundation of China (81871634 and 81301416), Postdoctoral Science Foundation of China (2014M561302 and 2015T80299), Norman Bethune Program of Jilin University (2015202), the Jilin Provincial Science and Technology Department (20140204004YY, 20160414025GH and 20190304064YY), and the Department of Human Resources and Social Security of Jilin Province (2016014).

\section{Conflict of Interest}

The authors declare no conflict of interest.

\section{References}

Carballo, C.M., Erro, M.G., Sordelli, N., Vazquez, G., Mistchenko, A.S., Cejas, C., Rodriguez, M., Cisterna, D.M., Freire, M.C., Contrini, M.M., et al. 2019. Acute flaccid myelitis associated with enterovirus D68 in children, argentina, 2016. Emerg. Infect. Dis. 25, 573-576.

Chang, S.C., Lin, J.Y., Lo, L.Y., Li, M.L., and Shih, S.R. 2004. Diverse apoptotic pathways in enterovirus 71-infected cells. J. Neurovirol. 10, 338-349.

Esposito, S., Zampiero, A., Ruggiero, L., Madini, B., Niesters, H., and Principi, N. 2015. Enterovirus D68-associated community-acquired pneumonia in children living in Milan, Italy. J. Clin. Virol. 68, 94-96.

Farrell, J.J., Ikladios, O., Wylie, K.M., O'Rourke, L.M., Lowery, K.S., Cromwell, J.S., Wylie, T.N., Melendez, E.L.V., Makhoul, Y., Sampath, R., et al. 2015. Enterovirus D68-associated acute respiratory distress syndrome in adult, United States, 2014. Emerg. Infect. Dis. 21, 914-916.

Gay, R.T., Belisle, S., Beck, M.A., and Meydani, S.N. 2006. An aged host promotes the evolution of avirulent coxsackievirus into a virulent strain. Proc. Natl. Acad. Sci. USA 103, 13825-13830.

Hardwick, J.M. 1998. Viral interference with apoptosis. Semin. Cell Dev. Biol. 9, 339-349.

Henderson, S., Huen, D., Rowe, M., Dawson, C., Johnson, G., and Rickinson, A. 1993. Epstein-Barr virus-coded BHRF1 protein, a viral homologue of Bcl-2, protects human B cells from programmed cell death. Proc. Natl. Acad. Sci. USA 90, 8479-8483.

Hengartner, M.O. 2000. The biochemistry of apoptosis. Nature 407, 770-776.
Holmes, K.V. 1975. Scanning electron microscopic studies of virus-infected cells. I. Cytopathic effects and maturation of vesicular stomatitis virus in L2 cells. J. Virol. 15, 355-362.

Kamau, E., Harvala, H., Blomqvist, S., Nguyen, D., Horby, P., Pebody, R., and Simmonds, P. 2019. Increase in enterovirus D68 infections in young children, United Kingdom, 2006-2016. Emerg. Infect. Dis. 25, 1200-1203.

Li, Z., Yu, J., Liu, L., Wei, Z., Ehrlich, E.S., Liu, G., Li, J., Liu, X., Wang, H., Yu, X., et al. 2014. Coxsackievirus A16 infection induces neural cell and non-neural cell apoptosis in vitro. PLoS ONE 9, e111174.

Lu, J.R., Lu, W.W., Lai, J.Z., Tsai, F.L., Wu, S.H., Lin, C.W., and Kung, S.H. 2013. Calcium flux and calpain-mediated activation of the apoptosis-inducing factor contribute to enterovirus 71-induced apoptosis. J. Gen. Virol. 94, 1477-1485.

Martin, U., Jarasch, N., Nestler, M., Rassmann, A., Munder, T., Seitz, S., Zell, R., Wutzler, P., and Henke, A. 2007. Antiviral effects of pan-caspase inhibitors on the replication of coxsackievirus B3. Apoptosis 12, 525-533.

Messacar, K. and Tyler, K.L. 2019. Enterovirus D68-associated acute flaccid myelitis: rising to the clinical and research challenges. JAMA 321, 831-832.

Oberste, M.S., Maher, K., Kilpatrick, D.R., Flemister, M.R., Brown, B.A., and Pallansch, M.A. 1999a. Typing of human enteroviruses by partial sequencing of VP1. J. Clin. Microbiol. 37, 1288-1293.

Oberste, M.S., Maher, K., Kilpatrick, D.R., and Pallansch, M.A. 1999 b. Molecular evolution of the human enteroviruses: correlation of serotype with VP1 sequence and application to picornavirus classification. J. Virol. 73, 1941-1948.

Rao, L., Modha, D., and White, E. 1997. The E1B 19K protein associates with lamins in vivo and its proper localization is required for inhibition of apoptosis. Oncogene 15, 1587-1597.

Reed, L.J. and Muench, H. 1938. A simple method of estimating fifty percent endpoints. Am. J. Epidemiol. 27, 493-497.

Reiche, J., Böttcher, S., Diedrich, S., Buchholz, U., Buda, S., Haas, W., Schweiger, B., and Wolff, T. 2015. Low-level circulation of enterovirus D68-associated acute respiratory infections, Germany, 2014. Emerg. Infect. Dis. 21, 837-841.

Richard, A. and Tulasne, D. 2012. Caspase cleavage of viral proteins, another way for viruses to make the best of apoptosis. Cell Death Dis. 3, e277.

Salvesen, G.S. and Dixit, V.M. 1997. Caspases: intracellular signaling by proteolysis. Cell $91,443-446$.

Shi, W., Li, X., Hou, X., Peng, H., Jiang, Q., Shi, M., Ji, Y., Liu, X., and Liu, J. 2012. Differential apoptosis gene expressions of rhabdomyosarcoma cells in response to enterovirus 71 infection. $B M C$ Infect. Dis. 12, 327.

Smura, T., Ylipaasto, P., Klemola, P., Kaijalainen, S., Kyllönen, L., Sordi, V., Piemonti, L., and Roivainen, M. 2010. Cellular tropism of human enterovirus D species serotypes EV-94, EV-70, and EV-68 in vitro: implications for pathogenesis. J. Med. Virol. 82, 1940-1949.

Song, F., Yu, X., Zhong, T., Wang, Z., Meng, X., Li, Z., Zhang, S., Huo, W., Liu, X., Zhang, Y., et al. 2018. Caspase-3 inhibition attenuates the cytopathic effects of EV71 infection. Front. Microbiol. 9, 817.

Villa, P., Kaufmann, S.H., and Earnshaw, W.C. 1997. Caspases and caspase inhibitors. Trends Biochem. Sci. 22, 388-393.

Wang, Z., Wang, Y., Wang, S., Meng, X., Song, F., Huo, W., Zhang, S., Chang, J., Li, J., Zheng, B., et al. 2018. Coxsackievirus A6 induces cell cycle arrest in G0/G1 phase for viral production. Front. Cell. Infect. Microbiol. 8, 279.

Wang, Z., Zhong, T., Wang, Y., Song, F., Yu, X., Xing, L., Zhang, W., Yu, J., Hua, S., and Yu, X. 2017. Human enterovirus 68 interferes with the host cell cycle to facilitate viral production. Front. Cell. Infect. Microbiol. 7, 29.

Wang, C., Zhou, R., Zhang, Z., Jin, Y., Cardona, C.J., and Xing, Z. 2015. Intrinsic apoptosis and proinflammatory cytokines regulated in human astrocytes infected with enterovirus 71. J. Gen. 
Virol. 96, 3010-3022.

Wurzer, W.J., Planz, O., Ehrhardt, C., Giner, M., Silberzahn, T., Pleschka, S., and Ludwig, S. 2003. Caspase 3 activation is essential for efficient influenza virus propagation. EMBO J. 22, 2717-2728.

Yu, J., Cui, Q., Jiang, Y., Yang, W., Tashiro, S., Onodera, S., and Ikejima, T. 2007. Pseudolaric acid B induces apoptosis, senescence, and mitotic arrest in human breast cancer MCF-7. Acta Pharmacol. Sin. 28, 1975-1983.

Yu, J., Wang, Z., Ren, P., Zhong, T., Wang, Y., Song, F., Hou, J., Yu, X., and Hua, S. 2017. Pseudolaric acid B inhibits the secretion of hepatitis B virus. Oncol. Rep. 37, 519-525.
Yu, J., Zhang, L., Ren, P., Zhong, T., Li, Z., Wang, Z., Li, J., Liu, X., Zhao, K., Zhang, W., et al. 2015. Enterovirus 71 mediates cell cycle arrest in S phase through non-structural protein 3D. Cell Cycle 14, 425-436.

Zhang, T., Ren, L., Luo, M., Li, A., Gong, C., Chen, M., Yu, X., Wu, J., Deng, Y., and Huang, F. 2015. Enterovirus D68-associated severe pneumonia, China, 2014. Emerg. Infect. Dis. 21, 916-918.

Zhang, S., Yu, X., Meng, X., Huo, W., Su, Y., Liu, J., Liu, Y., Zhang, J., Wang, S., and Yu, J. 2020. Coxsackievirus A6 induces necroptosis for viral production. Front. Microbiol. 11, 42. 